\title{
Analysis of the impact of climate change on groundwater related hydrological fluxes: a multi-model approach including different downscaling methods
}

\author{
S. Stoll ${ }^{1}$, H. J. Hendricks Franssen ${ }^{1,3}$, M. Butts ${ }^{2}$, and W. Kinzelbach ${ }^{1}$ \\ ${ }^{1}$ Institute of Environmental Engineering, ETH Zurich, 8093 Zurich, Switzerland \\ ${ }^{2}$ DHI Water and Environment, 2970 Hørsholm, Denmark \\ ${ }^{3}$ Agrosphere, ICG-4, Forschungszentrum Jülich GmbH, 52425 Jülich, Germany
}

Received: 20 September 2010 - Published in Hydrol. Earth Syst. Sci. Discuss.: 1 October 2010

Revised: 22 December 2010 - Accepted: 23 December 2010 - Published: 3 January 2011

\begin{abstract}
Climate change related modifications in the spatio-temporal distribution of precipitation and evapotranspiration will have an impact on groundwater resources. This study presents a modelling approach exploiting the advantages of integrated hydrological modelling and a broad climate model basis. We applied the integrated MIKE SHE model on a perialpine, small catchment in northern Switzerland near Zurich. To examine the impact of climate change we forced the hydrological model with data from eight GCM-RCM combinations showing systematic biases which are corrected by three different statistical downscaling methods, not only for precipitation but also for the variables that govern potential evapotranspiration. The downscaling methods are evaluated in a split sample test and the sensitivity of the downscaling procedure on the hydrological fluxes is analyzed. The RCMs resulted in very different projections of potential evapotranspiration and, especially, precipitation. All three downscaling methods reduced the differences between the predictions of the RCMs and all corrected predictions showed no future groundwater stress which can be related to an expected increase in precipitation during winter. It turned out that especially the timing of the precipitation and thus recharge is very important for the future development of the groundwater levels. However, the simulation experiments revealed the weaknesses of the downscaling methods which directly influence the predicted hydrological fluxes, and thus also the predicted groundwater levels. The downscaling process is identified as an important source of
\end{abstract}

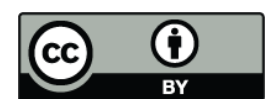

Correspondence to: S. Stoll (stoll@ifu.baug.ethz.ch) uncertainty in hydrological impact studies, which has to be accounted for. Therefore it is strongly recommended to test different downscaling methods by using verification data before applying them to climate model data.

\section{Introduction}

Climate change and the global water cycle are closely linked. Changes in the spatial and temporal distribution of precipitation and evapotranspiration as well as the implementation of adaptation strategies in agriculture and by ecosystems will have a direct impact on water resources. Studies with regional climate models (RCM) indicate that in Switzerland the frequency of dry summers like the drought of 2003 will increase during the 21st century (e.g., Schär et al., 2004). Studies based on the PRUDENCE data set (Christensen et al., 2007) show an expected decrease in the overall precipitation of $10 \%$ in Switzerland (until 2050), with an increase of winter precipitation and a decrease of summer precipitation (i.e. OcCC/PROCLIM, 2007). Additionally, an increase of air temperature will increase potential evapotranspiration. For Switzerland an increase of approximately 2 $3{ }^{\circ} \mathrm{C}$ is expected until 2050 (OcCC/PROCLIM, 2007). RCM calculations also suggest that the fraction of precipitation that is transformed into runoff will increase in the future related to an increased frequency of both extreme precipitation events and severe droughts (Schär et al., 2004; Frei et al., 2006). These phenomena will affect the hydrological system leading to changes in the temporal variability of discharge, changes in the spatio-temporal distribution of soil moisture and groundwater recharge and changes of water

Published by Copernicus Publications on behalf of the European Geosciences Union. 
stored in solid form (snow and glaciers). While the impact of climate change on surface water and lateral hydrological processes have been studied intensively (e.g., Arpe and Roeckner, 1999; Verbunt et al., 2006; Wang et al., 2008), the impact on subsurface hydrology, and especially groundwater, received much less attention in the scientific literature so far. However, probable decreases of groundwater resources due to higher evapotranspiration and less precipitation might significantly influence the drinking water supply. For Switzerland, due to the reduction of solid water storage the importance of aquifers for water storage and supply is increasing and the impact of climate change on groundwater is highly relevant for water resources management. Especially, small local aquifers which are used for drinking water supply and irrigation, may be very vulnerable. During the summer of 2003 a combination of high water demand and reduced recharge caused local problems with water suppliers being unable to meet demand. In particular, small water supplies, located in Central Switzerland and Ticino, which gain water from springs were affected. In several Swiss cantons authorities recommended saving water and prohibited using water for swimming pools, car washing and lawn sprinkling. Groundwater drawdowns of more than five meters were observed in some valley gravel aquifers, but water suppliers were less affected there because of the high antecedent groundwater levels (related to the wet winter 2002/2003). Also the use of lake water for water consumption alleviated the water supply situation (BUWAL, 2004). Besides the above-mentioned changes, changed human activities and adaptation of ecosystems to the changing climate must be considered. For instance, Fuhrer and Jasper (2009) state that as a reaction to more frequent droughts the water demand for agricultural irrigation in Switzerland will increase. A recent review on the relationship between groundwater and irrigation under climate change is given by Zhou et al. (2010). It is also very likely that the domestic water demand will increase, as seen during the summer drought in 2003.

Most aquifers for which the impact of climate change was studied are located in Northern America (e.g., Cohen et al., 2006; Scibek and Allen, 2006; Jyrkama and Sykes, 2007; Loáiciga, 2003; Allen et al., 2004) and Europe (e.g., Eckhardt and Ulbrich, 2003; Goderniaux et al., 2009). Fewer analyses were carried out for Australia (e.g., Green et al., 2007), Asia (e.g., Hsu et al., 2007) and Africa (e.g., Moustadraf et al., 2008). Most European studies predicted declines of the groundwater tables. For example, the water levels of an aquifer close to Grenoble were estimated to decrease up to four meters, making impossible the current practice of irrigated agriculture in the future (Bouraoui et al., 1999). A chalk aquifer in Belgium showed for some of the future climate scenarios a decline in groundwater levels of up to eight meters (Brouyère et al., 2004; Woldeamlak et al., 2007). These studies seem to be consistent with events like the summer drought of 2003 where in Switzerland rapid decreases in groundwater levels were observed. For example in a piezometer close to Uster, Canton of Zurich, the decrease was more than five meters in only 9 months. However, for Switzerland no thorough, model-based evaluation of the impact of climate change on groundwater resources has been carried out to date. As one of few, van Roosmalen et al. (2007) report groundwater level increases, due to increased winter precipitation. A more extensive literature review on the impact of climate change on groundwater resources is presented in Hendricks Franssen (2009).

Apart from the fact that the impact of climate change on groundwater resources has received limited attention in the scientific literature, the published studies have serious limitations. One problem is the way in which downscaling from a general circulation model (GCM) to a local hydrological model is made. Some hydrological studies which investigated the impact of climate change dealt with this problem more rigorously, for example by comparing the simulation results of a GCM in a reference period (typically the present climate) with a re-analysis data set (Scibek and Allen, 2006) or a measured time series (Loáiciga, 2003). Often, however, an even simpler approach is followed and some very general trends, extracted from a GCM, are used to generate future climate data. Today, the European project ENSEMBLES provides the possibility to force hydrological models with meteorological data from different GCM-RCM combinations where a dynamical downscaling is already performed. However, even those time series with a high spatial resolution $(25 \mathrm{~km})$ may provide biased estimates. The bias tends to show a complex temporal pattern. For example, often it is observed (by comparing model simulations with observations, e.g., Frei et al., 2006) that the frequency of precipitation events is overestimated, whereas the intensity is underestimated. For Switzerland it was also found that convective precipitation is underestimated and orographically enforced precipitation is overestimated. Therefore, an additional downscaling step is necessary when applying the data to local catchments or aquifers. This downscaling has to be applied both on precipitation and potential evapotranspiration calculated by the model. To address the impact of global change on groundwater resources it is crucial to estimate future time series of precipitation and actual evapotranspiration as these are governing the amount of recharge (especially for aquifers or parts of aquifers without strong interaction with streams). Actual evapotranspiration is strongly related to the soil moisture content. Therefore, following Goderniaux et al. (2009), we think it is essential to use integrated hydrological models coupling the unsaturated and saturated zone, when doing impact studies on groundwater resources.

With this study the impact of climate change on groundwater resources is addressed. A modelling approach is presented exploiting the advantages of integrated hydrological modelling and a broad climate model basis provided by the ENSEMBLES project. The sensitivity related to the downscaling procedure is of special interest in this study. 


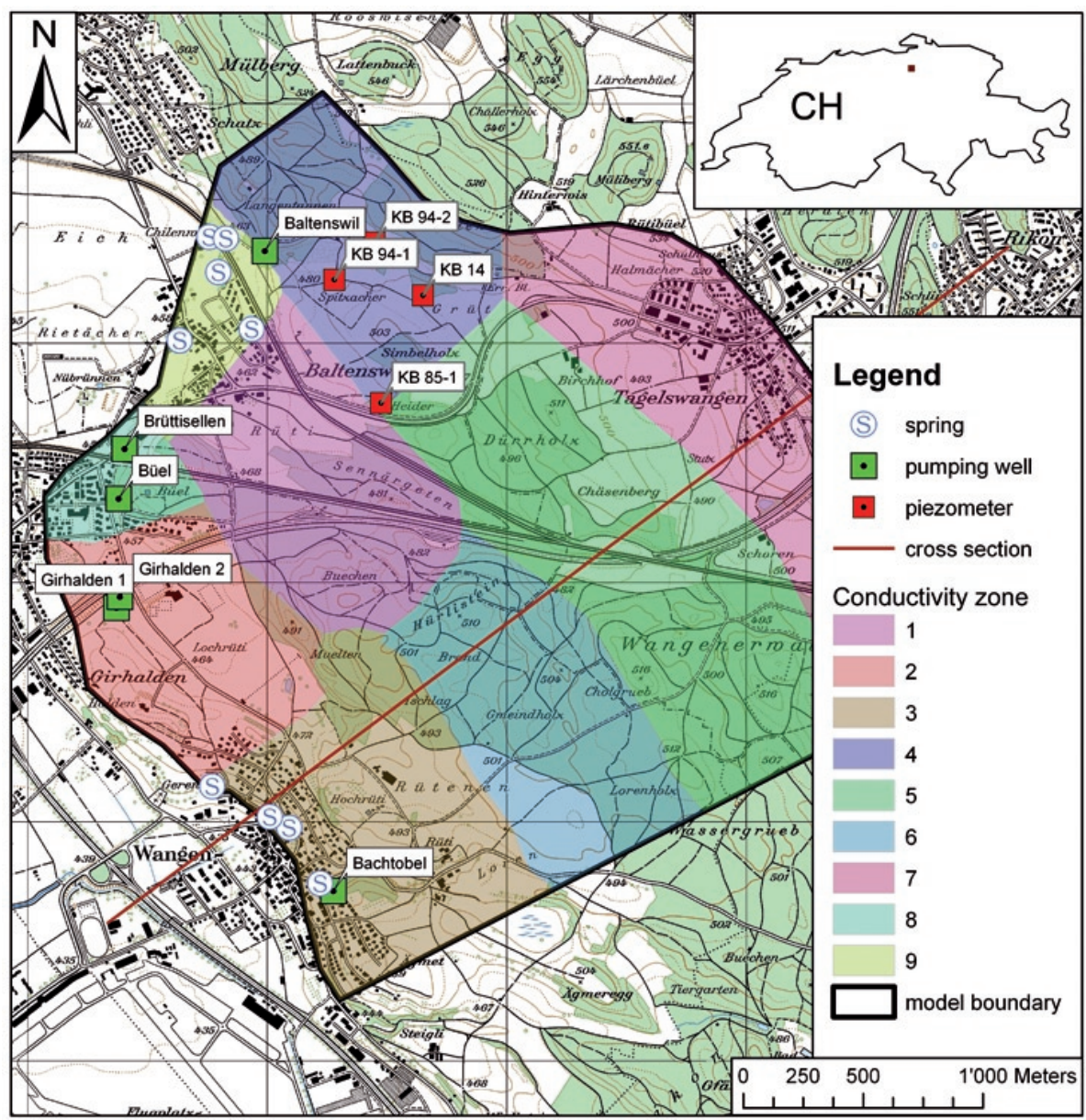

Fig. 1. Map of the study area with the locations of pumping wells (green square), piezometer (red square), springs (blue "S") and a geological cross section, specified in Fig. 2. The zones of the hydraulic conductivity are also shown.

The approach is tested in the small Baltenswil groundwater system in northern Switzerland near Zurich. There, drinking water is pumped and a significant drawdown was observed during the summer drought in 2003. As this aquifer is dominated by direct recharge it will be directly affected by changes in precipitation and evapotranspiration. A 3-D fully coupled surface water-groundwater hydrological model is built and calibrated. To examine the impact of climate change the hydrological model is forced with data from eight different RCM-GCM combinations, which are bias-corrected not only for precipitation but also for the variables that govern potential evapotranspiration. A major advantage of the ENSEMBLES database is that it provides data for the complete period 1961-2100 in daily resolution. This enables us to analyse not only specific time slices but also the evolution of the groundwater level for a period of 90 years (20102100). To gain insight into the sensitivity with respect to the downscaling procedure used, three different bias corrections are applied and the results are compared in terms of hydrological fluxes and the corresponding groundwater levels.
In contrast to most past impact studies we will also present a split sample evaluation for the applied downscaling approaches and will discuss the outcomes regarding the effects on the impact study results.

\section{Study area}

The Baltenswil area is located in northern Switzerland, within the Aathal aquifer in the upper Glatt valley and East of the city of Zurich (Fig. 1). The unconfined aquifer consists of highly conductive sands and gravels formed during the Riss ice age and is covered and laterally delimited by younger moraines of the Würm ice age. Weathered Molasse and lacustrine sediments, which are considered as impermeable, act as aquitard. The covering moraine layer has a spatially variable thickness between a few meters, close to the Western aquifer boundary to tens of meters in the north-eastern part (Fig. 2). It forms the characteristic hilly landscape with elevations from 440 to $530 \mathrm{~m}$ a.m.s.l. (above mean sea level). The aquifer supplies drinking water for 


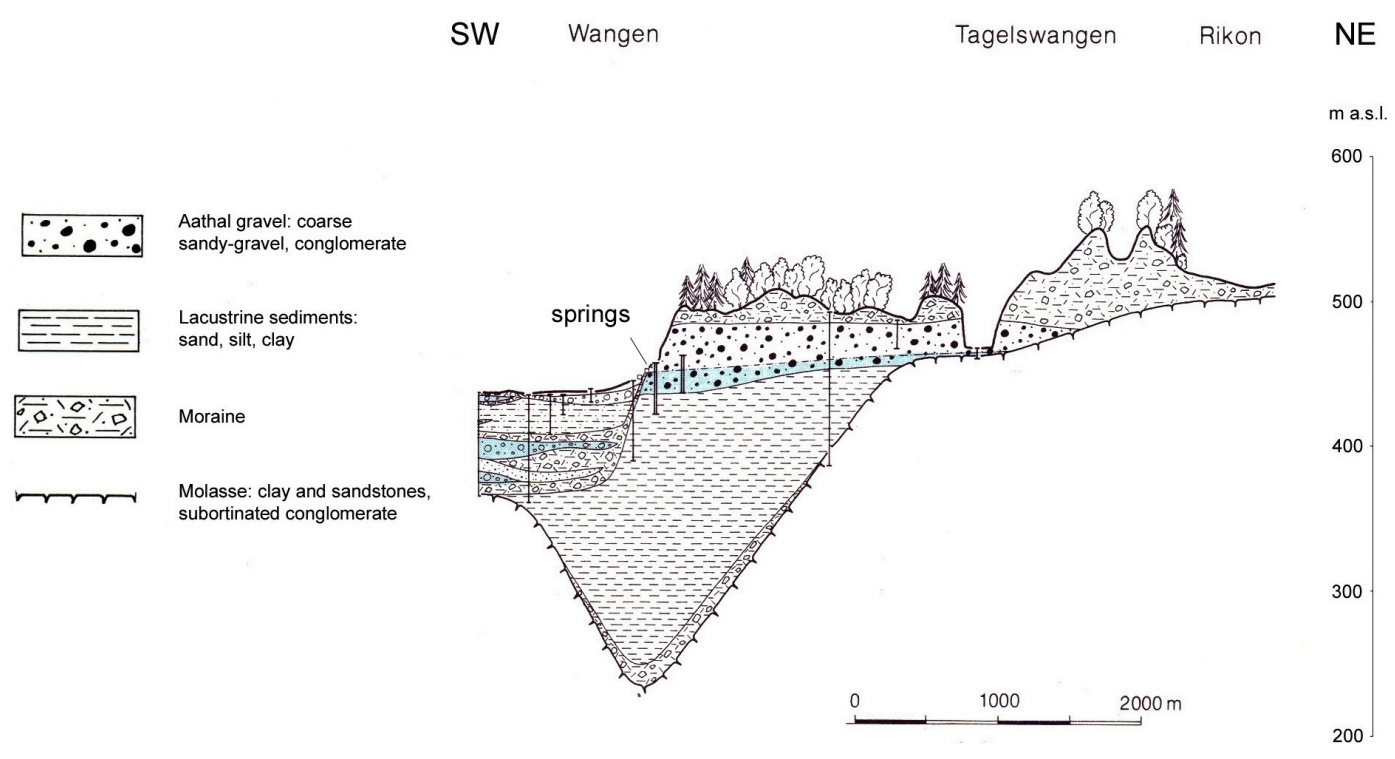

Fig. 2. Geological cross section as displayed in Fig. 1 (modified from SGK, 1986).

55000 people through six pumping stations. The summer drought in 2003 resulted in drawdowns of up to three meters and falling dry of some springs. However the local water supplier did not face problems due to large aquifer depth and the high antecedent groundwater levels. On the contrary, water from this aquifer was transferred to neighbouring drought affected water supplies.

Cambisols, with high permeability are the dominant soil type. This causes all precipitation to infiltrate into the underground. No permanent or ephemeral creek or stream is formed. If temporary surface runoff is created during extreme events or on frozen soil, it infiltrates again in local depressions within the area (run-on). The system discharges water only by a series of springs located at the western boundary of the aquifer. The area is used for forestry and agriculture to equal parts with a small area covered by settlements.

The study area is situated within the Swiss plateau, where a temperate climate prevails with a yearly average air temperature of $9{ }^{\circ} \mathrm{C}$ and a mean annual precipitation of around $1100 \mathrm{~mm}$ (average over the period 1961-1990). Precipitation data is obtained from the meteorological station Effretikon (480 m a.s.l.), $2.5 \mathrm{~km}$ north-east of the study area. Additional meteorological data are provided by Zurich-Kloten airport ( $436 \mathrm{~m}$ a.s.l.), which is located $6 \mathrm{~km}$ north-west of the study area.

\section{Methods}

\subsection{Hydrological model}

The model domain consists of the north-western part of the Aathal aquifer and includes an area of approximately $9 \mathrm{~km}^{2}$. In order to analyse the impact of climate change on this groundwater system we set up the integrated physically based hydrological model MIKE SHE (Graham and Butts, 2006). The model domain is discretized into grid cells of size $100 \mathrm{~m} \times 100 \mathrm{~m}$. The topography is represented by a digital elevation model with a spatial resolution of $50 \mathrm{~m}$.

Saturated groundwater flow is described by the groundwater flow equation based on Darcy's law and this equation is solved using an implicit finite differences technique. The Eastern boundary is chosen parallel to a groundwater flow line, which is assumed not to shift appreciably over time (this implies that an impervious boundary condition is used). Given the geological setting, the remaining boundaries are also considered as impervious. Based on the findings from a stochastic study by Onnis (2008) and pumping test data we divided the saturated part of the flow model in nine zones with constant hydraulic conductivity (Fig. 1). The values of the zones were calibrated with the help of a Shuffled Complex Evolution global optimization algorithm (Madsen, 2003) as implemented in the AUTOCAL tool of MIKE SHE (DHI, 2008) using historical head time series (1999-2002) from six wells and four piezometers. The periods 19951998 and 2003-2009 served for validation. The calibrated hydraulic conductivities as well as the prescribed values for specific yield and specific storage can be found in Table 1. It would have been preferable to perform the model calibration with an alternative technique, like sequential self-calibration 
method (Gómez-Hernández et al., 1997; Hendricks Franssen et al., 1999) that generates multiple equally likely spatially distributed parameter fields to the inverse problem, but this technique is not yet implemented in any integrated surfacesubsurface hydrological model.

The unsaturated zone is modelled as a vertical column on top of each aquifer cell, and is subdivided into 26 layers. The height of the layers varies from a few centimetres at the top to $5 \mathrm{~m}$ at the bottom of the unsaturated zone. Infiltration is calculated on the basis of precipitation, interception and snowmelt. The latter is simulated by a degree-day approach. Soil freezing is not implemented, which potentially could result in an overestimation of groundwater recharge, because precipitation in winter can infiltrate in MIKE-SHE, whereas in reality it would run-off. As argued before, in our study area the impact of this model limitation is not expected to be important. Due to the high conductivity of the soils and a water table depth of up to $40 \mathrm{~m}$, unsaturated flow is restricted to vertical gravity flow, neglecting capillary effects. The depth of the unsaturated zone is controlled by the groundwater table, allowing for a complete disappearance of the unsaturated zone when the groundwater table rises to the ground surface. The parameterization of the pressuresaturation relationships uses the methods of Mualem (1976) and van Genuchten (1980). The parameters were estimated according to information from soil maps and field data (Table 1).

Potential evapotranspiration is calculated with the Penman-Monteith method, according to the guidelines of the FAO (Allen et al., 1998). Based on that, the model of Kristensen and Jensen (1975) calculates actual evapotranspiration as a function of soil moisture and the leaf area index (LAI). The required parameters were specified according to literature values and are listed in Table 1 for the two land use types.

\subsection{Climate change scenarios and downscaling}

The calibrated model is used to investigate the impacts of climate change on the Baltenswil groundwater system. Vegetation parameters have a predefined annual cycle and this cycle is assumed to be constant over the simulation period until 2100. Average values for water abstraction are applied. We use RCM data of the European Union Sixth Framework Programme project ENSEMBLES (Hewitt and Griggs, 2004). Seven RCMs (Table 2) which are driven by five different GCMs were selected from the available model pool. Unfortunately, the ENSEMBLES database does not contain a significant number of climate models for all scenarios except the A1B scenario. All models use the SRES A1B scenario (Nakicenovic et al., 2000), which is moderate in terms of $\mathrm{CO}_{2}$ emissions. Models provide data of all relevant meteorological variables in daily time steps until 2100 and at a spatial resolution of $25 \mathrm{~km}$. Although RCMs deliver relatively high resolution outputs in space and time, this may not
Table 1. Parameters used in the integrated hydrological model MIKE-SHE for the Baltenswil catchment.

\begin{tabular}{|c|c|c|}
\hline evapotranspiration & agriculture/pasture & forest \\
\hline Root depth $L_{\mathrm{r}}(\mathrm{m})$ & 0.5 & 2.5 \\
\hline Max. LAI (-) & 3 & 8 \\
\hline Canopy interception $c_{\text {int }}(\mathrm{mm})$ & 0.05 & 0.05 \\
\hline Empirical coeff. $c_{1}(-)$ & 0.3 & 0.3 \\
\hline Empirical coeff. $c_{2}(-)$ & 0.2 & 0.2 \\
\hline Empirical coeff. $c_{3}(\mathrm{~mm} / \mathrm{d})$ & 20 & 20 \\
\hline Root mass distribution AROOT (1/m) & 1 & 1 \\
\hline \multicolumn{3}{|l|}{ Unsaturated zone } \\
\hline Residual water content $\theta_{\mathrm{r}}(-)$ & 0.02 & \\
\hline Saturated water content $\theta_{\text {sat }}(-)$ & 0.3 & \\
\hline Van Genuchten parameter $\alpha_{\mathrm{r}}(1 / \mathrm{cm})$ & 0.03 & \\
\hline Van Genuchten parameter $n(-)$ & 2 & \\
\hline Van Genuchten parameter $l(-)$ & 0.5 & \\
\hline Saturated hydraulic conductivity $k_{\mathrm{sat}}(\mathrm{m} / \mathrm{s})$ & 0.001 & \\
\hline \multicolumn{3}{|l|}{ Saturated zone } \\
\hline Specific yield $S(-)$ & 0.25 & \\
\hline Specific storage $S_{\mathrm{S}}(\mathrm{m} / \mathrm{s})$ & 0.0001 & \\
\hline Hydraulic conductivity zone $1 k_{\text {sat }}(\mathrm{m} / \mathrm{s})$ & $9.510^{-5}$ & \\
\hline Hydraulic conductivity zone $2 k_{\text {sat }}(\mathrm{m} / \mathrm{s})$ & $4.610^{-3}$ & \\
\hline Hydraulic conductivity zone $3 k_{\text {sat }}(\mathrm{m} / \mathrm{s})$ & $5.410^{-4}$ & \\
\hline Hydraulic conductivity zone $4 k_{\text {sat }}(\mathrm{m} / \mathrm{s})$ & $3.610^{-3}$ & \\
\hline Hydraulic conductivity zone $5 k_{\text {sat }}(\mathrm{m} / \mathrm{s})$ & $4.810^{-3}$ & \\
\hline Hydraulic conductivity zone $6 k_{\text {sat }}(\mathrm{m} / \mathrm{s})$ & $3.210^{-4}$ & \\
\hline Hydraulic conductivity zone $7 k_{\text {sat }}(\mathrm{m} / \mathrm{s})$ & $1.510^{-3}$ & \\
\hline Hydraulic conductivity zone $8 k_{\text {sat }}(\mathrm{m} / \mathrm{s})$ & $3.310^{-3}$ & \\
\hline Hydraulic conductivity zone $9 k_{\text {sat }}(\mathrm{m} / \mathrm{s})$ & $2.110^{-4}$ & \\
\hline
\end{tabular}

be sufficient when applying them in regional hydrological impact studies. Therefore we perform three different downscaling methods, not only for precipitation but also for the variables that govern potential evapotranspiration (air temperature, global radiation, wind speed, humidity and surface pressure). The downscaling approaches were selected, because they are widely used in the hydrological community and have different deficiencies, which will be discussed in detail at a later point. The following downscaling methods were applied on the time series produced by the RCMs:

1. Factor Correction. This method is widely used in hydrological impact studies (e.g., Fowler and Kilsby, 2007; Kleinn et al., 2005; Durman et al., 2001). Monthly additive (air temperature) and multiplicative (all other meteorological variables) correction factors are calculated by a comparison between the monthly mean values of the climate model and the monthly means of the observation data during a reference period (1961-2000). Those correction factors are then added to/multiplied with the daily values for the future scenario as computed by the climate models. It is assumed that the correction factors estimated with the help of data from the past can also be applied to time series of future meteorological variables. This method is very easy to implement and 
Table 2. Climate models.

\begin{tabular}{lll}
\hline Institution & RCM & GCM \\
\hline Danish Meteorological Institute (DMI) & HIRHAM5 & ECHAM5 \\
Max Planck Institute for Meteorology (MPI) & M-REMO & ECHAM5 \\
Royal Netherlands Meteorological Institute (KNMI) & RCA & ECHAM5-r3 \\
Swedish Meteorological and Hydrological Institute (SMHI) & RACMO2 & ECHAM5-r3, BCM \\
Hadley Center for Climate Prediction and Research (HC) & HadRM3Q0 & HadCM3Q0 \\
Institute for Atmospheric and Climate Science, ETH Zurich (ETH) & CLM & HadCM3Q0 \\
Community Climate Change Consortium for Ireland (C4I) & RCA3 & HadCM3Q16 \\
\hline
\end{tabular}

provides a bias correction on a monthly basis. However, this approach does not account for differences in the variability.

2. Annual CDF correction. In order to account for changes in variability a second well-known method (e.g., Déqué, 2007; Michelangeli et al., 2009) based on an empirical transfer function is applied. $D_{\mathrm{o}}$ is the cumulative probability density function (CDF) of a climate variable $x$ (e.g. precipitation), observed at a weather station for a given reference period (again 1961-2000). $D_{\mathrm{mC}}$ is then the CDF of the RCM output for the same variable and period. To downscale a specific daily climate model value $x_{\mathrm{mC}}$ we identify the observed value $x_{\mathrm{o}}$ which has the same probability:

$D_{\mathrm{o}}\left(x_{o}\right)=D_{\mathrm{mC}}\left(x_{\mathrm{mC}}\right)$

which is equivalent to

$x_{\mathrm{o}}=D_{\mathrm{o}}^{-1}\left(D_{\mathrm{mC}}\left(x_{\mathrm{mC}}\right)\right)$

where $D_{\mathrm{o}}^{-1}$ is the inverse function of $D_{\mathrm{o}}$.

By applying this relationship to the future climate model data $x_{\mathrm{mF}}$ (2001-2100) we obtain a bias corrected data set which also reflects the differences in variability. As the CDFs are discrete empirical functions, linear interpolation becomes necessary for $x_{\mathrm{mF}}$ located between two calibrated points $x_{\mathrm{mC}}$. For values exceeding (e.g. for precipitation) or falling below (e.g. for humidity) the boundaries of $x_{\mathrm{mC}}$ we apply the same relative relationship as between the nearest $x_{\mathrm{mC}}-x_{\mathrm{o}}$ pair. Again, we assume that the biases are stationary in time.

3. Monthly CDF Correction. At last we perform the CDF Correction on a monthly basis combing the strengths of the two previous methods. This time, the empirical relationship (Eq. 2) is not established for the whole calibration period in total, but for each of the twelve months separately. Thus twelve empirical transfer relationships were determined, which are applied to the future climate model outputs, with a different relationship for each of the twelve months.
To analyse the performance of the three downscaling approaches, the period from 2001-2009 will serve for validation.

The results will be displayed as the average output variable values of the eight climate models with the corresponding maxima and minima. The average is calculated with equal weights for the different climate models. With this multi model approach we try to reflect the uncertainties of the climate models in impact studies. However, we have to keep in mind that there are several other sources of uncertainty which are not considered. Uncertainties related with different emission scenarios and internal variability of climate models, as well as the uncertainty of the hydrological model (e.g. parameter uncertainty) and of adaptation processes (e.g. vegetation changes) are not accounted for. For example, changes in the length of the phenological cycle (Menzel et al., 2006) as well as prolonged summer drought stress (Brolsma et al., 2010) could have considerable impact on evapotranspiration.

\section{Results}

\subsection{Hydrological model}

The observed and simulated groundwater heads are given in Fig. 3. For both the calibration and the validation periods the modelled and observed heads are in good correspondence at most of the observation wells. This is also shown by the performance criteria presented in Table 3. For seven out of ten wells the calibration resulted in a mean absolute error equal to or less than one meter. Also the inter- and intra-annual variations and dynamics are reproduced satisfactorily, which is confirmed by the quite high correlation coefficients. Only the pumping stations Girhalden 1 and Girhalden 2, and to a lesser extent Büel, show less satisfactory results. This may be directly related to the pumping activity. Varying pumping rates result in significant variations in the water level in very short time (see Fig. 3). For example, at Girhalden the pump is runnig every day, by default. Spikes in groundwater level occur, when the pump is shut down (e.g. for maintenance). These variations act on a small scale and are the direct consequence of local pumping activity and do not represent the 

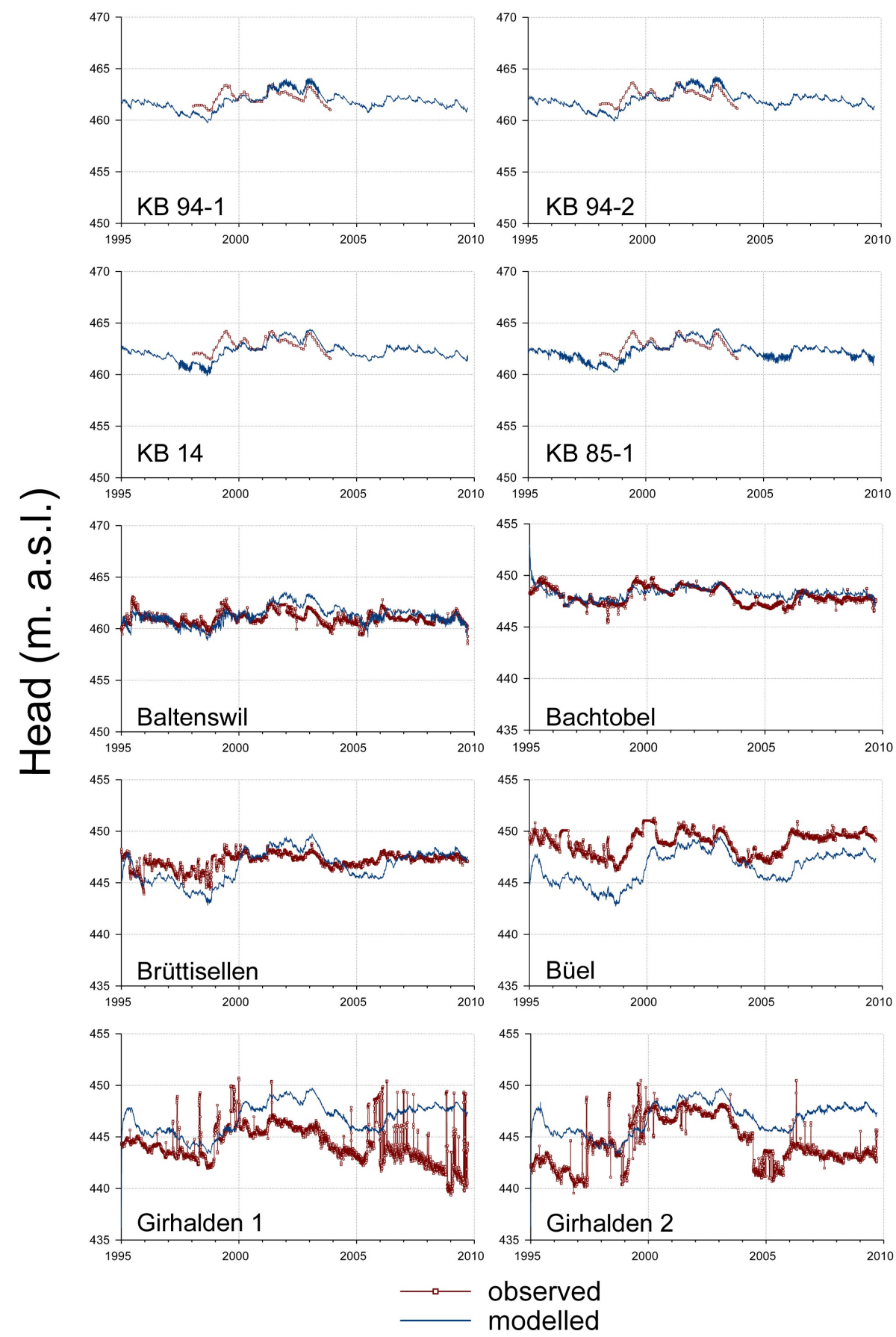

Fig. 3. Observed (red) and modelled (blue) groundwater heads. The period 1999-2002 served for calibration.

general flow field. The model resolution of $100 \mathrm{~m}$ is too coarse to resolve such small-scale effects and consequently biases in the absolute water levels occur. However, groundwater level dynamics are less affected and are still represented well. We did not use a finer resolution because this would drastically increase the number of grid cells and the required CPU-times were already substantial because calculations were carried out for a long period and with input from different climate models and downscaling approaches. We assume that the model only locally deviates from the measured hydraulic heads and is well suited for this regional scale exercise.

Although there is no quantitative information, the comparison between mapped and simulated locations of spring outflow can be used to evaluate the consistency of the conceptual model structure. Figure 4 shows the cells where the 


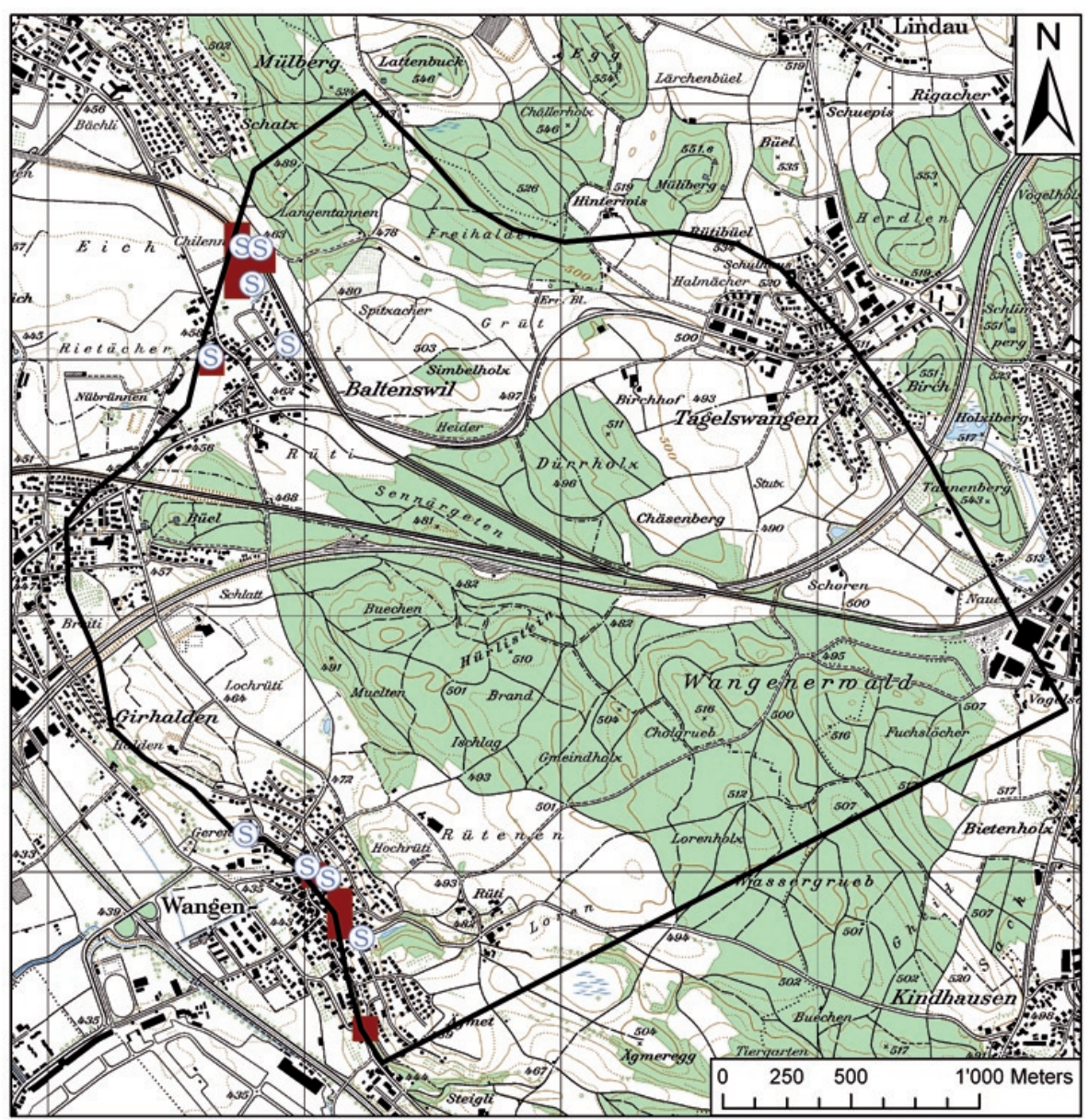

Fig. 4. Locations of mapped springs (blue "S") and cells generating spring outflow (red).

Table 3. Performance criteria of groundwater modeling: Comparison between simulated and observed groundwater heads for the period 1995-2010.

\begin{tabular}{lrcc}
\hline Observation well & Mean error (m) & $\begin{array}{c}\text { Mean absolute } \\
\text { error }(\mathrm{m})\end{array}$ & $\begin{array}{c}\text { Correlation } \\
\text { coefficient }\end{array}$ \\
\hline KB 94-1 & +0.01 & 0.66 & 0.70 \\
KB 94-2 & -0.01 & 0.63 & 0.68 \\
KB 14 & +0.22 & 0.66 & 0.70 \\
KB 85-1 & -0.50 & 0.82 & 0.71 \\
Baltenswil & -0.27 & 0.62 & 0.61 \\
Bachtobel & -0.26 & 0.50 & 0.66 \\
Brüttisellen & +0.43 & 1.00 & 0.70 \\
Büel & +2.37 & 2.37 & 0.66 \\
Girhalden 1 & -2.48 & 2.83 & 0.21 \\
Girhalden 2 & -2.43 & 2.65 & 0.53 \\
\hline
\end{tabular}

simulation model produces spring discharge from the saturated zone (on 31 July 2000). The locations match well with the two major areas where spring outflow occurs.

\subsection{Climate models and downscaling}

The time period 2001-2009 is used for verifying the different downscaling methods, which were calibrated using the period 1961-2000. The verification is carried out in terms of the bias of the average daily modelled precipitation $\overline{P_{\mathrm{m}}}$ compared to the observed precipitation $\overline{P_{\mathrm{O}}}(3.2 \mathrm{~mm} / \mathrm{d})$ :

$\Delta \bar{P}=\overline{P_{\mathrm{m}}}-\overline{P_{\mathrm{o}}}$

Correspondingly, also the bias between the standard deviation of the observed precipitation $\Delta \sigma_{P \mathrm{o}}(6.7 \mathrm{~mm} / \mathrm{d})$ and the modelled standard deviation of the daily precipitation $\Delta \sigma_{P \mathrm{~m}}$ is calculated:

$\Delta \sigma_{P}=\sigma_{P \mathrm{~m}}-\sigma_{P \mathrm{o}}$

$\Delta \bar{P}$ and $\Delta \sigma_{P}$ vary strongly among the different models and differ often substantially from zero, which is indicative of a bad performance (Table 4). Some models like the ETH model overestimate the average precipitation, where others like the KNMI model underestimate it. Figure 5 shows the observed and modelled exceedance probabilities of the daily 
Table 4. Biases of daily precipitation $(\Delta \bar{P})$ and standard deviation $\left(\Delta \sigma_{P}\right)$ for the verification period 2001-2009. Observed daily precipitation $(3.2 \mathrm{~mm} / \mathrm{d})$ and corresponding standard deviation $(6.7 \mathrm{~mm} / \mathrm{d})$ serve as reference. The period 1961-2000 was used for the calibration of the downscaling methods.

\begin{tabular}{lcccccccc}
\hline & \multicolumn{2}{c}{ Uncorrected (mm) } & \multicolumn{2}{c}{ Factor Correction (mm) } & \multicolumn{2}{c}{ CDF Correction (mm) } & \multicolumn{2}{c}{ Monthly CDF Correction (mm) } \\
& $\Delta \bar{P}$ & $\Delta \sigma_{P}$ & $\Delta \bar{P}$ & $\Delta \sigma_{P}$ & $\Delta \bar{P}$ & $\Delta \sigma_{P}$ & $\Delta \bar{P}$ & $\Delta \sigma_{P}$ \\
\hline DMI & -0.7 & -1.9 & -0.1 & -0.5 & -0.2 & -0.2 & -0.1 & +0.2 \\
MPI & 0 & -0.7 & -0.2 & -1.0 & -0.2 & +0.1 & -0.2 & +0.3 \\
KNMI & -0.8 & -2.3 & -0.2 & -0.9 & -0.2 & -0.1 & -0.2 & -0.4 \\
SMHI-ECHAM & -0.2 & -1.8 & -0.1 & -1.4 & -0.1 & -0.1 & -0.1 & -0.5 \\
SMHI-BCM & -0.6 & -2.3 & +0.2 & -0.6 & +0.2 & +0.1 & +0.2 & +0.3 \\
HC & +0.7 & +0.3 & 0 & -0.7 & 0 & +0.2 & 0 & -0.1 \\
ETH & +0.7 & +0.3 & -0.1 & -0.5 & -0.1 & +0.1 & -0.2 & -0.6 \\
C4I & -0.9 & -2.4 & +0.4 & +1.3 & +0.1 & +0.1 & +0.3 & +1.0 \\
\hline Sum of absolute changes & +4.6 & +12.0 & +1.3 & +6.9 & +1.1 & +1.0 & +1.3 & +3.4 \\
\hline
\end{tabular}
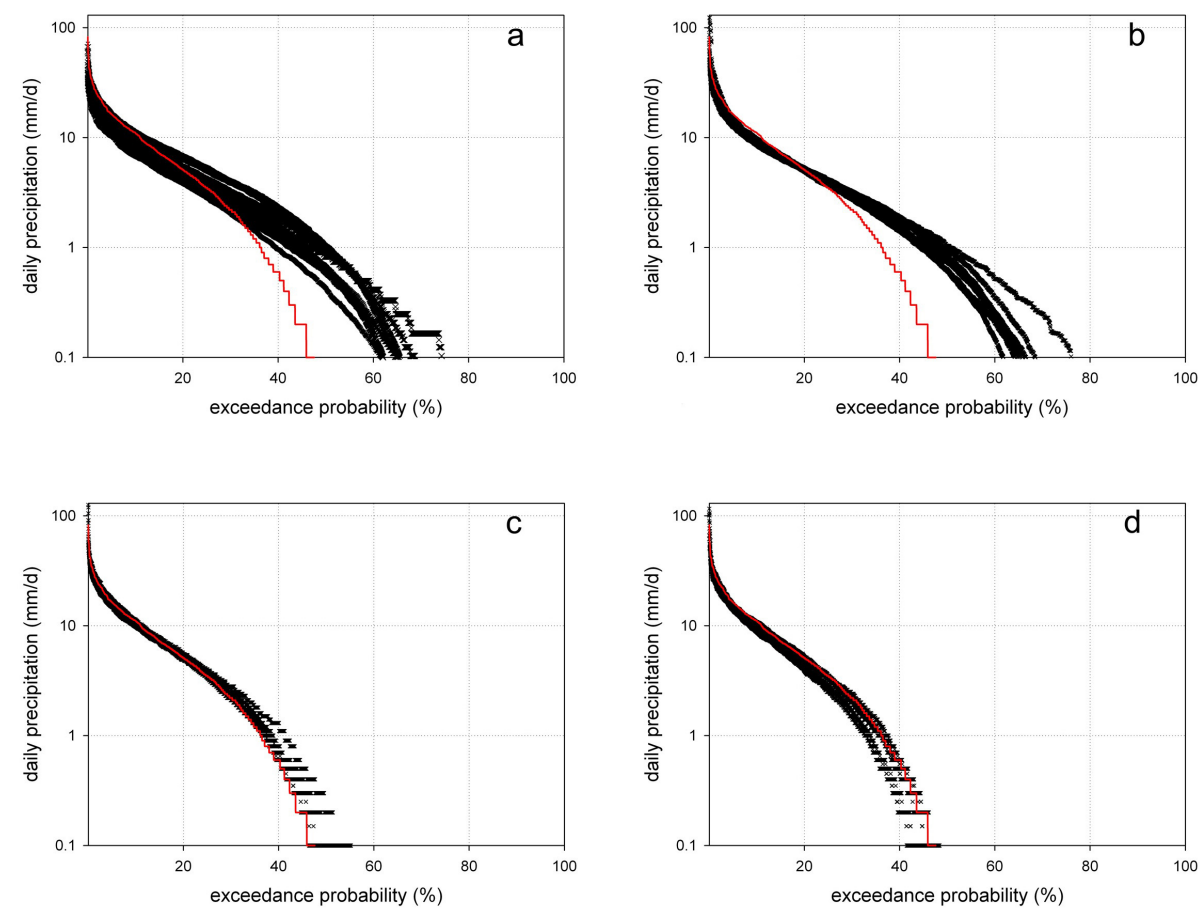

modelled

observed

Fig. 5. Observed and modelled exceedance probabilities of daily precipitation - uncorrected climate model data (a), Factor Correction (b), CDF Correction (c) and monthly CDF Correction (d) - for the verification period 2001-2009.

precipitation sum for the same period. The figure illustrates that none of the climate models is able to represent the distribution correctly. The models show a strong tendency to overestimate small precipitation amounts and underestimate large precipitation sums. Through the application of the Factor Correction the range of the model outputs as well as the average biases were reduced significantly. Although the general representation of the variability could be improved, the RCMs still overestimate the small amounts and the number of days with precipitation. Both CDF Corrections are able to correct the bias in average precipitation bias and the underestimation of the variability. However, the annual CDF Correction performs slightly better than the monthly, especially in the representation of the standard deviation. 

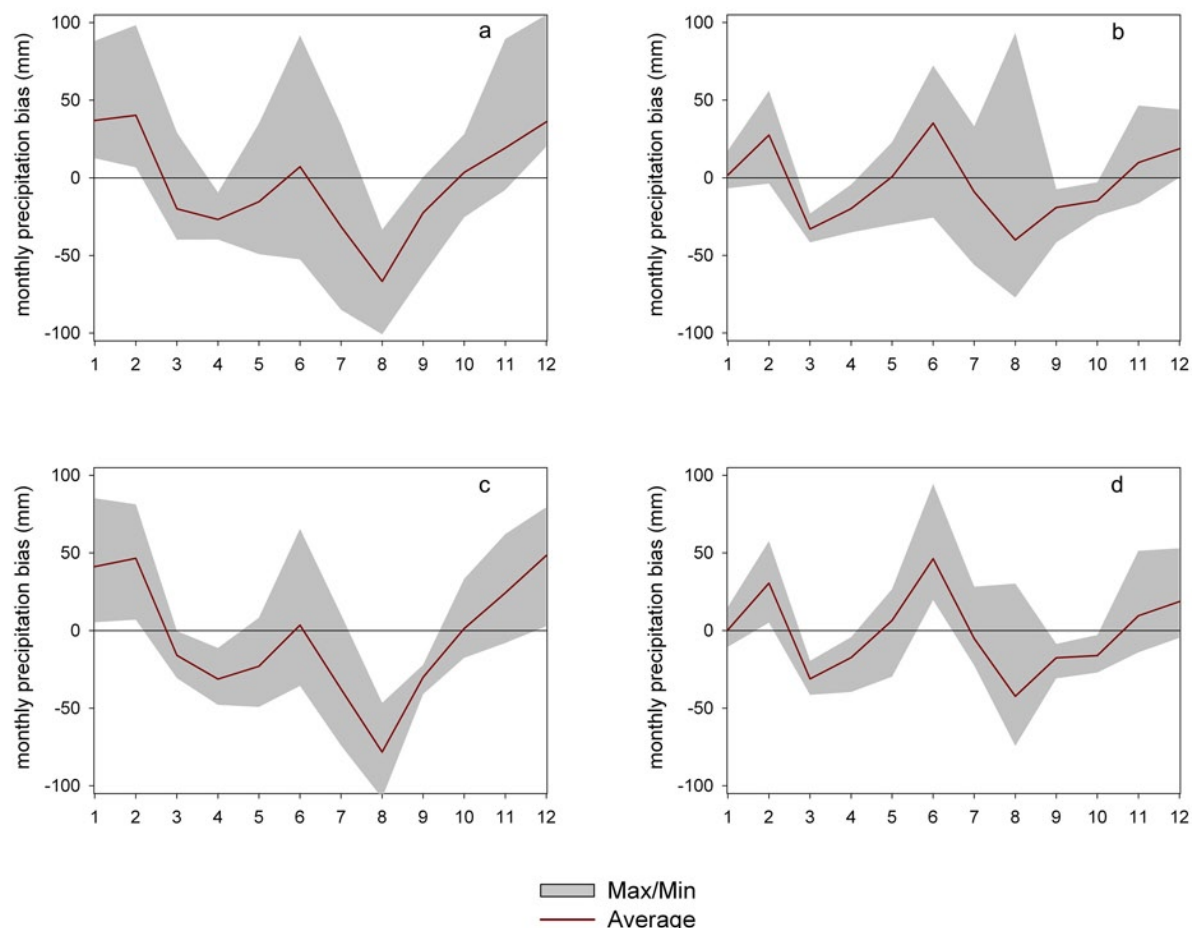

Fig. 6. Biases of monthly precipitation sum - uncorrected climate model data (a), Factor Correction (b), CDF Correction (c) and monthly CDF Correction (d) - during the verification period 2001-2009. The numbers on the x-axis represent the months of the year.

If we focus on the intra-annual distribution of the biases presented in Fig. 6, it becomes apparent that although the average annual values are represented quite well, large deviations of the monthly precipitation sum occur. The uncorrected climate model data and the annual CDF Correction show the typical deficiencies of an overestimation of winter precipitation and an underestimation of summer precipitation (e.g., Frei et al., 2006). The Factor Correction and the monthly CDF Correction are able to strongly reduce those monthly biases, but the general pattern is still visible.

Figure 7 shows the predicted monthly changes for the period 2071-2100 of precipitation, air temperature and potential evapotranspiration for the uncorrected model predictions and the model predictions corrected with the downscaling methods. The observed values of the climate normal 19612000 are used as a reference for the changes as it is usually assumed (Goderniaux et al., 2009) that the "(...) bias correction of each climate scenario reflects control simulation biases relative to observations (...)" and thus the future changes can be expressed relative to observed climate data or to simulations driven by observed data. Changes for the uncorrected climate model data are presented relative to the outputs of the models during the reference period. Potential evapotranspiration is calculated with the PenmanMonteith method, using observed air temperature, humidity, wind speed and global radiation data for the period 19812000. The restriction to 1981-2000 was necessary as no
Table 5. Average annual sums of precipitation $(P)$, potential evapotranspiration (PET), actual evapotranspiration (AET), recharge $(R)$, water extractions (Ext), spring outflow $(S)$ and the average temperature $(T)$ and head $(h)$.

\begin{tabular}{lllllllll}
\hline & $\begin{array}{l}P \\
(\mathrm{~m})\end{array}$ & $\begin{array}{l}\text { PET } \\
(\mathrm{mm})\end{array}$ & $\begin{array}{l}\text { AET } \\
(\mathrm{mm})\end{array}$ & $\begin{array}{l}R \\
(\mathrm{~mm})\end{array}$ & $\begin{array}{l}\text { Ext } \\
(\mathrm{mm})\end{array}$ & $\begin{array}{l}S \\
(\mathrm{~mm})\end{array}$ & $\begin{array}{l}T \\
\left({ }^{\circ} \mathrm{C}\right)\end{array}$ & $\begin{array}{l}h \\
(\mathrm{~m})\end{array}$ \\
\hline $\begin{array}{l}\text { Control } \\
\text { period }\end{array}$ & 1135 & 675 & 552 & 588 & 285 & 298 & 8.7 & 458 \\
\hline
\end{tabular}

global radiation data were available before 1981. The average values of the water balance for the control period are given in Table 5. The results of the annual changes for the individual climate models are presented in Table 6 .

A shift of the intra-annual precipitation distribution, with wetter winters and drier summers can be observed. However, this pattern is less distinctive for the monthly corrections. Although an increase in winter precipitation is simulated, hardly any decrease during summer is apparent. Contrary to this, the annual CDF correction shows a very distinctive intra-annual shift, even stronger than in the uncorrected data. Regarding the annual precipitation and potential evapotranspiration amounts, large differences can be seen among the uncorrected individual climate models. Through the downscaling process most increases in annual precipitation are 
Table 6. Changes in annual precipitation $(\Delta P)$, mean yearly potential evapotranspiration ( $\Delta$ PET) and mean yearly air temperature $(\Delta T)$ for the period 2071-2100 (compared with the reference period as specified in the text).

\begin{tabular}{lrrrrrrrrrr}
\hline & & DMI & MPI & KNMI & $\begin{array}{r}\text { SMHI } \\
\text { ECHAM }\end{array}$ & $\begin{array}{r}\text { SMHI } \\
\text { BCM }\end{array}$ & HC & ETH & C4I & average \\
& & & & & & & \\
& $\Delta P(\mathrm{~mm})$ & +139 & +37 & +129 & +105 & +133 & +71 & -133 & +39 & +65 \\
Uncorrected & $\Delta T\left({ }^{\circ} \mathrm{C}\right)$ & +2.4 & +3.1 & +3.1 & +2.8 & +2.1 & +4.2 & +3.8 & +4.5 & +3.2 \\
& $\Delta$ PET $(\mathrm{mm})$ & +30 & +88 & +87 & +49 & +8 & +174 & +92 & +69 & +75 \\
\hline \multirow{5}{*}{ Factor Correction } & $\Delta P(\mathrm{~mm})$ & +142 & +19 & +137 & +84 & +152 & +76 & -105 & +147 & +82 \\
& $\Delta T\left({ }^{\circ} \mathrm{C}\right)$ & +2.5 & +3.3 & +3.2 & +2.3 & +2.3 & +4.3 & +4.0 & +4.7 & +3.3 \\
& $\Delta \mathrm{PET}(\mathrm{mm})$ & +13 & +52 & +73 & +24 & -2 & +122 & +54 & +37 & +47 \\
\hline \multirow{5}{*}{ CDF Correction } & $\Delta P(\mathrm{~mm})$ & +197 & +81 & +217 & +176 & +226 & +101 & -84 & +82 & +125 \\
& $\Delta T\left({ }^{\circ} \mathrm{C}\right)$ & +2.5 & +3.4 & +3.2 & +3.3 & +2.4 & +3.7 & +3.5 & +4.5 & +3.3 \\
& $\Delta \mathrm{PET}(\mathrm{mm})$ & -2 & +38 & +63 & +43 & -4 & +101 & +22 & +26 & +36 \\
\hline \multirow{5}{*}{ Monthly CDF Correction } & $\Delta P(\mathrm{~mm})$ & +171 & +76 & +196 & +135 & +216 & +99 & -86 & +139 & +120 \\
& $\Delta T\left({ }^{\circ} \mathrm{C}\right)$ & +2.1 & +3.2 & +2.8 & +2.9 & +2.3 & +3.5 & +3.5 & +4.3 & +3.1 \\
& $\Delta \mathrm{PET}(\mathrm{mm})$ & +1 & +48 & +58 & +28 & +2 & +106 & +24 & +21 & +36 \\
\hline
\end{tabular}
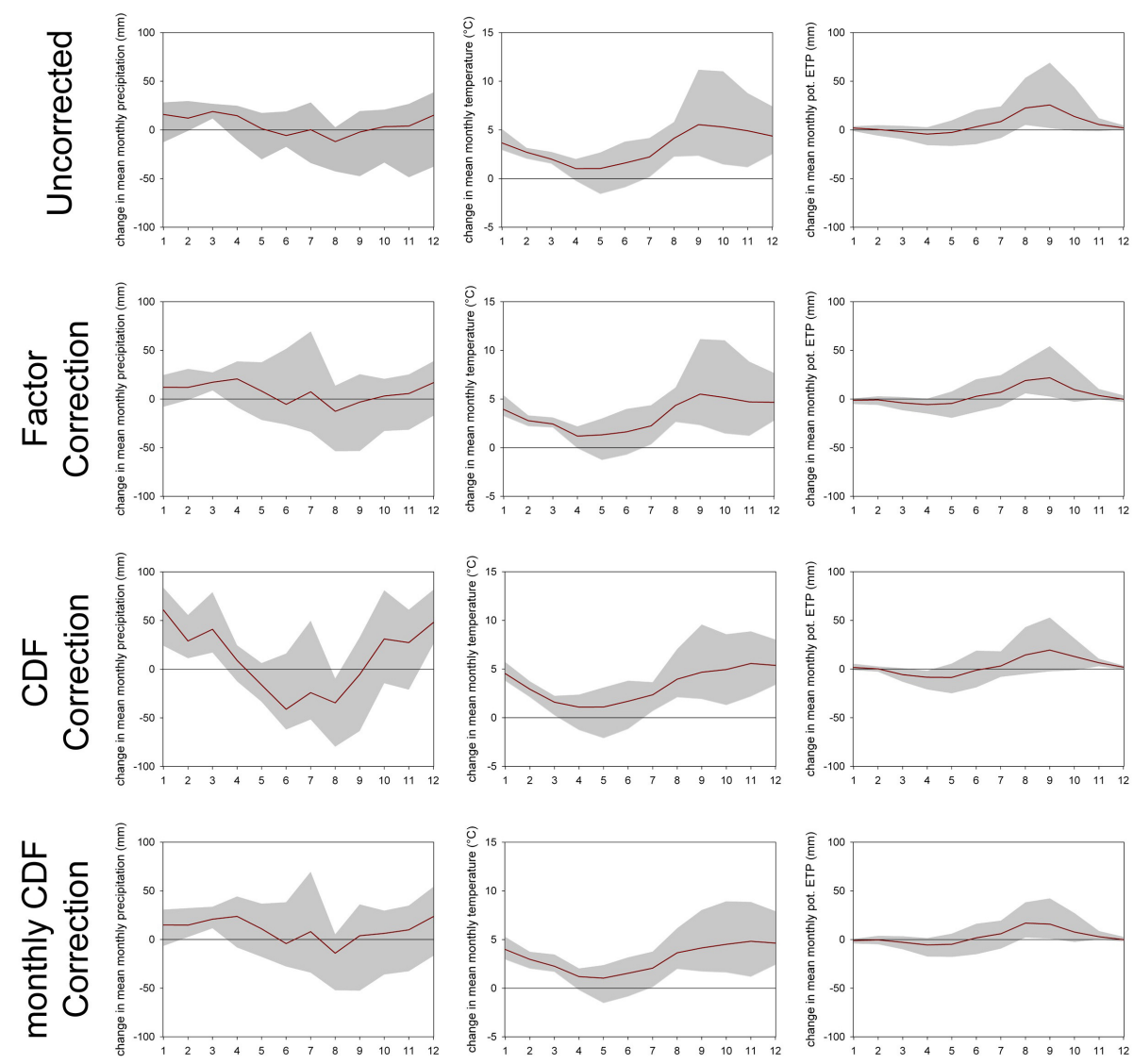

Fig. 7. Averaged changes in monthly precipitation (first column), mean air temperature (second column) and potential evapotranspiration (third column). 

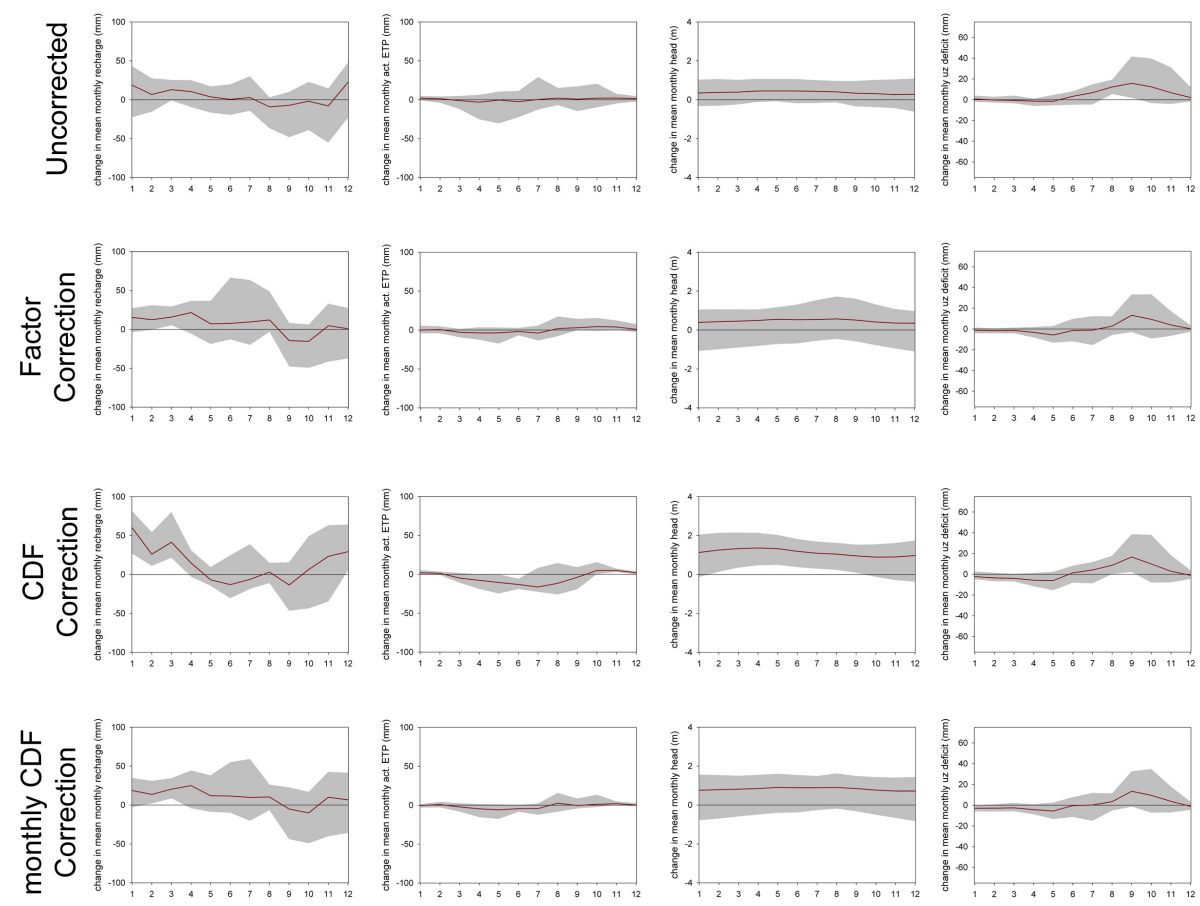

Fig. 8. Averaged changes in monthly recharge amounts (first column), actual evapotranspiration (second column), hydraulic head (third column) and water deficit in the unsaturated zone (fourth column).

amplified and only the ETH model predicts a decrease in the annual precipitation sum. The CDF Corrections predict higher increases than the Factor correction. Apart from the reduction of the output range, no big differences between the raw and downscaled temperatures can be observed. All models predict an annual temperature increase which is especially strong in late summer, autumn and winter. The trends of the potential evapotranspiration generally follow the regime of the air temperature. However, the increase is less significant than that of the air temperature. For the Factor Correction one (SMHI-BCM) and for the annual CDF Correction two models (DMI, SMHI-BCM) even predict a slight decrease of the annual potential ET sum. All downscaling approaches result, as expected, in a reduction of the differences among the climate models.

\subsection{Impact on groundwater resources}

To evaluate the changes in the hydrological fluxes and the groundwater table we compare the results of the period 2071-2100 with a model control run (1981-2000) driven by observation data. Changes for the uncorrected case are presented relative to the outcomes of the hydrological model, driven by the outputs of the climate models during the reference period. Figure 8 shows the monthly changes in actual evapotranspiration, recharge and average groundwater table depth. Also the relative change in the water deficit of the unsaturated root zone is shown. It is defined as the amount of water which is necessary to bring the soil moisture conditions to field capacity. Table 7 shows the changes of the average yearly recharge sum, actual evapotranspiration sum and average groundwater table depth for each of the climate models.

The results show that the intra-annual distribution of actual evapotranspiration is not affected much by climate change according to the model predictions. Most distinctive is a small reduction during the summer. However, considerable differences in the annual actual evapotranspiration amounts among the individual climate models can still be observed. The results obtained for recharge are closely related with those obtained for precipitation and actual evapotranspiration. The uncorrected data and the data downscaled according to the annual CDF Correction show an intensified yearly cycle in the period 2071-2100 compared to the reference period. Recharge is increased during winter but reduced in the summer period. The results for the monthly corrections do not show such a pronounced change in the yearly cycle of the recharge amounts.

The applications of the bias corrections result in an increasing groundwater table, which contrasts with other climate change impact assessment studies on groundwater resources in Europe showing a decreasing trend (e.g., Brouyère et al., 2004). In general, the bias correction also results in a reduced variability of these predictions. The intra-annual shift of the groundwater levels is different among the downscaling methods and the average increase of the groundwater 
Table 7. Changes in mean annual recharge $(\Delta R)$, mean yearly actual evapotranspiration ( $\Delta$ AET) and mean yearly hydraulic head $(\Delta h)$ for the period 2071-2100 (compared with the reference period as specified in the text).

\begin{tabular}{llrrrrrrrrr}
\hline & & DMI & MPI & KNMI & $\begin{array}{r}\text { SMHI } \\
\text { ECHAM }\end{array}$ & SMHI & HCM & ETH & C4I & average \\
& & & & & & & \\
\hline \multirow{3}{*}{ Uncorrected } & $\Delta R(\mathrm{~mm})$ & +91 & +65 & +134 & +126 & +95 & -42 & -44 & -9 & +5 \\
& $\Delta$ AET $(\mathrm{mm})$ & +43 & -39 & +24 & 0 & +42 & +58 & -116 & +30 & -29 \\
& $\Delta h(\mathrm{~m})$ & +0.47 & +0.23 & +1.03 & +0.87 & +0.81 & -0.21 & -0.10 & -0.10 & +0.38 \\
\hline \multirow{3}{*}{ Factor Correction } & $\Delta R(\mathrm{~mm})$ & +124 & +27 & +135 & +84 & +131 & +20 & -68 & +170 & +78 \\
& $\Delta$ AET $(\mathrm{mm})$ & +7 & +21 & -9 & -10 & +9 & +46 & -44 & -35 & -2 \\
& $\Delta h(\mathrm{~m})$ & +0.89 & +0.10 & +1.00 & +0.52 & +1.01 & +0.02 & -0.80 & +1.21 & +0.49 \\
\hline \multirow{3}{*}{ CDF Correction } & $\Delta R(\mathrm{~mm})$ & +231 & +114 & +240 & +195 & +248 & +75 & +24 & +194 & +165 \\
& $\Delta$ AET $(\mathrm{mm})$ & -46 & -44 & -36 & -32 & -35 & +15 & -118 & -124 & -53 \\
& $\Delta h(\mathrm{~m})$ & +1.58 & +0.59 & +1.69 & +1.24 & +1.84 & +0.52 & +0.13 & +1.38 & +1.12 \\
\hline \multirow{3}{*}{ Monthly CDF Correction } & $\Delta R(\mathrm{~mm})$ & +160 & +90 & +201 & +148 & +198 & +70 & -43 & +160 & +122 \\
& $\Delta$ AET (mm) & +3 & -24 & -18 & -25 & -6 & +19 & -51 & -33 & -16 \\
& $\Delta h(\mathrm{~m})$ & +1.16 & +0.44 & +1.45 & +0.97 & +1.50 & +0.46 & -0.51 & +1.16 & +0.82 \\
\hline
\end{tabular}

levels is much larger with the annual CDF Correction than with the Factor Correction method. As for the precipitation, the monthly CDF Correction falls within this range. All climate models corrected with the annual CDF approach predict an increase of the groundwater table. Groundwater levels also rise if downscaling is done according to the monthly correction methods, but increases are smaller in general and for one of the models (ETH) a groundwater level decrease is expected. Although an increase of the groundwater table is estimated, increased water stress in the root zone during summer and autumn is predicted by the climate models. For winter and spring, no significant changes of the water deficit are found.

The temporal evolution of the groundwater level at the observation borehole KB14 from 2000 to 2100 is given in Fig. 9. The borehole KB14 was selected because it is not situated near the pumping wells, so that it is less affected by high frequency variations imposed by pumping activity. Additionally, the dynamics of the groundwater level at KB14 represent well the general behavior of the whole aquifer. The hydrological model driven by uncorrected data shows large uncertainty related to the climate models. Moreover, significant biases compared to the measured water levels can be observed. The application of the factor correction reduces this bias as well as the spread between the different climate models. However, the inter-annual variability is less pronounced. In contrast to that the annual CDF Correction delivers a good fit of the observed levels as well as an adequate representation of the variability. Again, the results of the monthly CDF Correction lie between the other two methods.
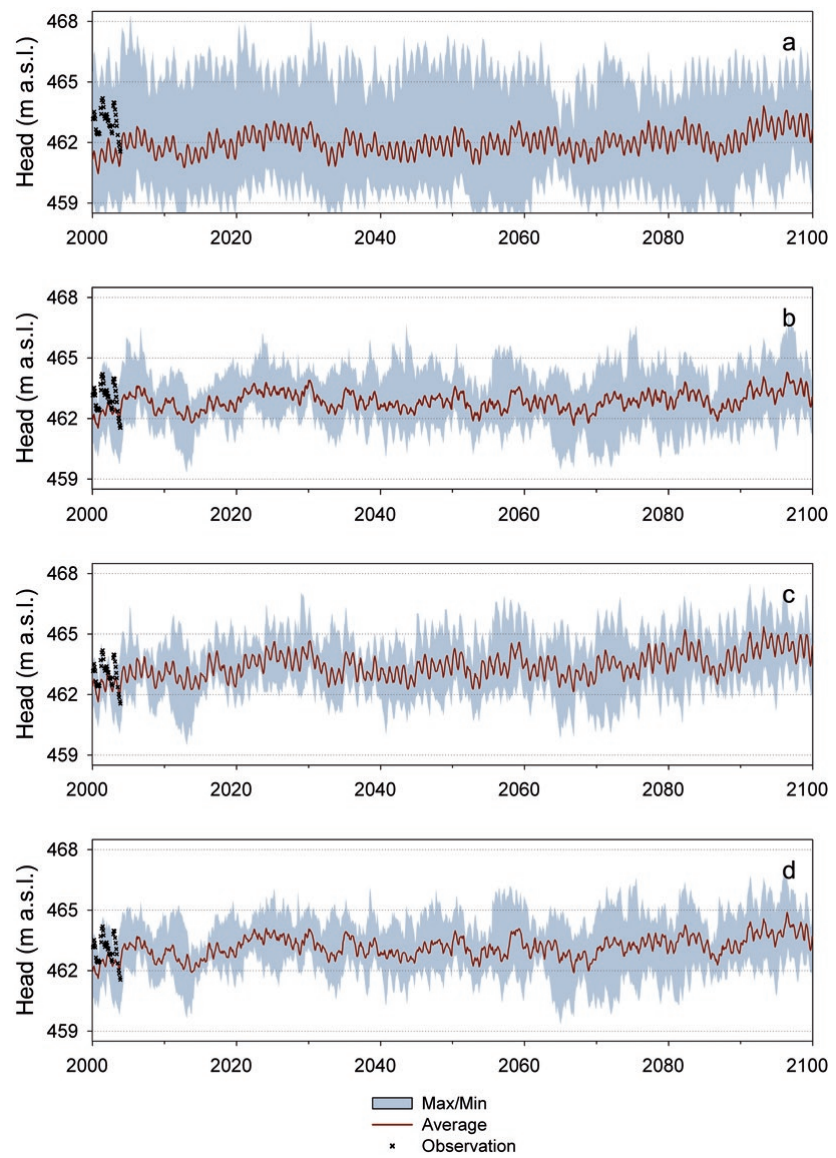

Fig. 9. Evolution of the hydraulic head at KB 14 - uncorrected climate data (a), factor correction (b), CDF correction (c) and monthly CDF Correction (d) - until 2100. 


\section{Discussion}

\subsection{Climate models and downscaling}

The large differences between the output of climate models and observations make it necessary to use downscaling approaches when conducting hydrological impact studies. We compared three downscaling methods, widely known and used in the hydrological community and evaluated the performance of them for the period 2001-2009. The application of the Factor Correction method for downscaling is quite effective in correcting for monthly biases of temperature, precipitation and potential evapotranspiration. However, this method did not reproduce well the occurrence of extreme precipitation events and the number of days without any precipitation. The CDF Correction on the other hand explicitly accounts for the variability and, hence, shows good agreement for both the average annual values and the representation of the variability. However, the deviations of the monthly precipitation sums could not be reduced and showed the same pattern as the uncorrected climate model data. The monthly CDF Correction is kind of a trade-off between the two. It reduces the monthly biases while also providing a reasonable representation of the variability.

The main problem of all the downscaling approaches is their weak physical basis as they do not take into account the precipitation generating mechanisms behind the data. For instance, the underestimation of summer precipitation might be related to the fact that in climate models the amount of convective precipitation is underestimated. If under future climate conditions summer precipitation would be generated even more by convective events, and less by orographic enforced precipitation, this underestimation would be even stronger in the future. For hydrological applications it would therefore be important to consider alternative downscaling methods that take into account the atmospheric flow pattern. The bias correction can be performed as a function of the atmospheric circulation patterns. In that case, the atmospheric circulation has to be classified in a number of different classes, with the help of atmospheric model variables like geopotential height, pressure gradients in different spatial directions, integrated vapour content and others (e.g., Boé et al., 2009). Another alternative to the presented rather simple downscaling approaches would be the use of weather generators, which are especially relevant if not the complete daily times series is available from the climate models. Weather generators are extremely useful to produce stochastic time series on the basis of global change statistics. However, problems in representing extreme events and inter-annual variations are still present (Katz and Parlange, 1998).

Keeping in mind the deficiencies of the downscaling approaches we also analysed the projected future changes for the period 2071-2100. The first thing to recognize is the wide spread between the uncorrected individual climate models, not only in the amplitude but also in the trend of the estimated annual precipitation changes. Especially the uncertainty related to the precipitation is very high. This is a very convincing argument against impact studies using the outputs of just one climate model and without any downscaling. After the application of the downscaling approaches, most climate models agree on an increase of the annual precipitation, compared to the uncorrected data. However, the question is whether this change is really related to a physically based change in precipitation or if this can be attributed to the downscaling procedure itself.

At first glance, the changes in precipitation appear reasonable and seem to be consistent with results from previous studies (e.g., Schmidli et al., 2007). The difference to past studies (e.g., OcCC/PROCLIM, 2007) evaluating the impacts of climate change in Switzerland is only the fact, that the winter increase in precipitation exceeds the summer decrease. This may be directly related to the climate model basis (i.e. PRUDENCE vs. ENSEMBLES). But if we compare Figs. 6 and 7 it seems that the trends in the monthly precipitation sums are clearly correlated to the errors of the downscaling approaches. Especially precipitation data which were not subject of a monthly correction show intra-annual changes which are quite similar to the pattern of the biases during the evaluation period. Also the magnitude of the errors is of the same size as the expected changes. It seems that some downscaling procedures are not able to account for the model biases. Therefore a comparison with observed values as a reference is problematic for assessing future changes, when the correction approach is not effective in removing the biases. Downscaling procedures not explicitly accounting for the seasonal errors (like the annual CDF Correction) have to be used with caution. A physically based downscaling or at least seasonal corrections seem to be necessary for reaching more reliable results when analysing recharge. It is important that the downscaling method matches the main relevant characteristics of precipitation. While the intra-annual representation is very important for groundwater management, a reasonable representation of extreme events is crucial for flood prevention.

Other meteorological variables (like air temperature) are less affected by downscaling driven effects because the raw climate model already gives a good estimate by reproducing the past observed temperatures more satisfactorily. Hardly any difference between raw and downscaled data can be found for the mean monthly temperatures. All climate models predict an increase which is less distinctive during spring and early summer. Not surprisingly, potential evapotranspiration seems to be related to the changes of temperature. During winter only little evapotranspiration takes place. Accordingly, the absolute changes are also expected to be small and few differences among the climate models can be seen. The uncertainty concerning potential evapotranspiration in summer is larger, which is closely related to the more elevated potential evapotranspiration in summer. Two climate models (SMHI-BCM, DMI), predict a decrease of annual potential 
ET. This could be related with a reduction of the incoming radiation, which has a larger impact on potential ET than the increase of air temperature.

\subsection{Impact on groundwater resources}

The shift of the intra-annual distribution of recharge is clearly dominated by the changes of precipitation. As no surface runoff is leaving the system, precipitation either recharges or is converted to evapotranspiration. Therefore also the problems related to the downscaling have direct influence on the hydrological fluxes, and thus on the groundwater level.

The changes of precipitation and actual evpotranspiration in the uncorrected climate models result in different trends for recharge and thus also groundwater levels. This uncertainty can be reduced by the Factor Correction where almost all models predict an increase in water level. However, whereas the raw climate model runs showed a decrease of summer recharge and an increase of winter recharge, the intra-annual trend almost disappears if downscaling according to the factor method is applied. On the other hand the annual CDF correction follows the trend of the uncorrected climate data, resulting in an even stronger increase of the groundwater levels compared to the Factor correction. The reduction of precipitation during summer has only little influence on recharge, as nearly all water is lost as evapotranspiration. Similar to the results presented in van Roosmalen et al. (2007), more precipitation in winter directly increases recharge as hardly any water is lost to evapotranspiration. However, due to the above-mentioned problems with the downscaling method these results are highly uncertain. Although we assume that the downscaling accounts for the deviations between climate model output and observation, some biases, especially on a monthly scale were not removed. It seems that the intensification is related to this remaining bias of the monthly precipitation rather than being a physical change in the precipitation distribution. By taking into account the distribution of the biases, the monthly CDF Correction avoids these problems. Accordingly, the increase of the groundwater table is smaller and hardly any intensification of the annual recharge cycle can be observed. The soil water deficit during the late summer, as opposed to the recharge, does not seem to be affected dramatically by the downscaling process. Raw climate model data as well as the three downscaling approaches show a similar behaviour. Although potential evapotranspiration is assumed to increase, actual evapotranspiration shows no positive trend. The reduction of precipitation during summer and an associated reduction of the soil moisture content of the root zone result in a decrease of actual evapotranspiration.

The description of the complete evolution of the groundwater level reveals the uncertainties derived from different climate models if no downscaling is applied. Generally the uncorrected climate models underestimate the groundwater level which is a consequence of the underestimation of the annual precipitation sum. Also large differences between maximum and minimum groundwater levels can be observed, which are related to the differences between the individual climate models. Through the application of the downscaling approaches, the bias and the uncertainties can be reduced. However, the deficiency of the Factor Correction becomes prominent. It is not able to represent the interannual variability correctly. The factor method results in a small increase of the predicted groundwater levels during the 21 st century. The application of the annual CDF correction results in an even more pronounced increase in groundwater levels, with no indication of an increased risk of extreme groundwater droughts. However, given the unsatisfactory representation of the annual cycle within the annual CDF method, those results have to be considered with caution. Here again, the monthly CDF Correction combines the strengths of the other two downscaling approaches. It only shows a moderate increase of the groundwater level by avoiding the incorrect intensification of the recharge cycle but also reveals the problems in describing the maxima and minima values.

Generally, none of the downscaling methods predicts future groundwater stress for the Baltenswil aquifer system and only minor changes of evapotranspiration are expected. It becomes apparent that especially the distribution of precipitation over the year has a major influence on the evolution of the groundwater.

\section{Conclusions}

We have seen that it is difficult to assess the possible impacts of climate change on groundwater resources. It is impossible to carry out an impact study without any downscaling as the differences among the climate models and the deviations between climate models and observed precipitation data are huge. After applying three downscaling methods, no future groundwater stress is predicted. This is in clear contrast to most of the earlier European studies that predicted decreasing groundwater levels in a future climate (e.g., Bouraoui et al., 1999). The reasons for those contradictions are (1) the different generations of climate models, (2) local differences, (3) the use of downscaling methods in our study and (4) the fact that we used an integrated hydrological model. Not only different climate models but also the applied downscaling methods and the choice of the reference have serious implications for the conclusions drawn from the hydrological studies. A high sensitivity to the intra-annual distribution of the hydrological fluxes became apparent. Schmidli et al. (2007) stated that "(...) downscaling does significantly contribute to the uncertainty in regional climate scenarios(...)". Therefore we strongly recommend testing different downscaling methods by using verification data before applying them on climate model data. It is crucial to evaluate the performance 
with respect to the representation of average values, the variability but also the intra-annual distribution.

Based on those uncertainties we think that it is currently very difficult to make reliable statements about the impact of climate change on specific groundwater resources by driving hydrological models with climate model outputs. Especially the poor performance of the climate models in reproducing the intra-annual regime may be an essential obstacle. One may argue that more sophisticated downscaling approaches would perform better than the presented rather simple methods. This is probably true, however apart from the abovementioned problems of the climate models and downscaling there are still many other sources of uncertainties which are not considered in most impact studies so far. Hydrologists are still struggling with the problem of uncertainty in hydrological modelling. Sociologists and economists face serious uncertainties in predicting future emissions of greenhouse gases and water demand. And in plant physiology scientists are still debating if climate change enhances or diminishes the annual transpiration sum (e.g., Tricker et al., 2009; Polley et al., 2008).

We recommend, that the assessment of climate change impact should not focus solely on driving hydrological models with climate change signals derived from climate models. Alternatively, we suggest using historical data to analyse how hydrological systems have reacted under significant historical changes in climatic conditions. Historical time series of e.g. groundwater levels contain valuable proxy information on past changes in recharge and their relation with vegetation and climate conditions. Analyzing those data could help to identify processes (e.g. a possible shift in the intra-annual distribution of precipitation) which will affect groundwater resources in the future. Historical data indicate, that especially reduced winter precipitation causes large groundwater level declines (Warren, 1994; Bradford, 2000). However, it is essential to relate observed patterns in historical data not only to climate but also to land use changes and anthropogenic activity.

Acknowledgements. We thank Henrik Madsen and Sara Lerer from DHI for their advice. The study was supported by SNF Project No. 200021_121862. The ENSEMBLES data used in this work was funded by the EU FP6 Integrated Project ENSEMBLES (Contract number 505539) whose support is gratefully acknowledged.

Edited by: A. Guadagnini

\section{References}

Allen, D. M., Mackie, D. C., and Wei, M.: Groundwater and climate change: a sensitivity analysis for the Grand Forks aquifer, Southern British Columbia, Canada, Hydrogeolog. J., 12, 270290, 2004.

Allen, G. A., Pereira, L. S., Raes, D., and Smith, M.: Crop Evapotranspiration - guidelines for Computing Crop Water Requirements, FAO Irrigation and Drainage Paper, 56, 78-86, 1998.
Arpe, K. and Roeckner, E.: Simulation of the hydrological cycle over Europe: Model validation and impacts of increasing greenhouse gases, Adv. Water Resour., 23, 105-119, 1999.

Boé, J., Terray, L., Martin, E., and Habets, F.: Projected changes in components of the hydrological cycle in French river basins during the 21st century, Water Resour. Res., 45, W08426, doi:10.1029/2008wr007437, 2009.

Bouraoui, F., Vachaud, G., Li, L. Z. X., Le Treut, H., and Chen, T.: Evaluation of the impact of climate changes on water storage and groundwater recharge at the watershed scale, Clim. Dynam., 15, 153-161, 1999.

Bradford, R. B.: Drought events in Europe, in: Drought and Drought Mitigation in Europe, edited by: Vogt, J. V. and Somma, F., Kluwer Academic Publishers, 2000.

Brolsma, R. J., van Vliet, M. T. H., and Bierkens, M. F. P.: Climate change impact on a groundwater-influenced hillslope ecosystem, Water Resour. Res., 46, W11503, doi:10.1029/2009wr008782, 2010.

Brouyère, S., Carabin, G., and Dassargues, A.: Climate change impacts on groundwater resources: modelled deficits in a chalky aquifer, Geer basin, Belgium, Hydrogeolog. J., 12, 123-134, 2004.

BUWAL: Auswirkungen des Hitzesommers 2003 auf die Gewässer, Schriftenreihe Umwelt Nr. 369, Bundesamt für Umwelt, Wald und Landschaft, Bern, 2004.

Christensen, J. H., Carter, T. R., Rummukainen, M., and Amanatidis, G.: Evaluating the performance and utility of regional climate models: the PRUDENCE project, Climatic Change, 81(Suppl. 1), 1-6, 2007.

Cohen, D., Person, M., Daannen, R., Locke, S., Dahlstrom, D., Zabielski, V., Winter, T. C., Rosenberry, D. O., Wright, H., Ito, E., Nieber, J. L., and Gutowski, J. W. J.: Groundwater-supported evapotranspiration within glaciated watersheds under conditions of climate change, J. Hydrol., 320, 484-500, 2006.

Déqué, M.: Frequency of precipitation and temperature extremes over France in an anthropogenic scenario: Model results and statistical correction according to observed values, Global Planet. Change, 57, 16-26, 2007.

DHI: AUTOCAL, Autocalibration Tool, User Guide, DHI Water \& Environment, Denmark, 2008.

Durman, C. F., Gregory, J. M., Hassell, D. C., Jones, R. G., and Murphy, J. M.: A comparison of extreme European daily precipitation simulated by a global and a regional climate model for present and future climates, Q. J. Roy. Meteor. Soc., 127, 1005$1015,2001$.

Eckhardt, K. and Ulbrich, U.: Potential impacts of climate change on groundwater recharge and streamflow in a central European low mountain range, J. Hydrol., 284, 244-252, 2003.

Fowler, H. and Kilsby, C.: Using regional climate model data to simulate historical and future river flows in northwest England, Climatic Change, 80, 337-367, 2007.

Frei, C., Schöll, R., Fukutome, S., Schmidli, J., and Vidale, P. L.: Future change of precipitation extremes in Europe: Intercomparison of scenarios from regional climate models, J. Geophys. Res., 111, D06105, doi:10.1029/2005jd005965, 2006.

Fuhrer, J. and Jasper, K.: Bewässerungsbedürftigkeit von Ackerund Grasland im heutigen Klima, Agrarforschung, 16(10), 396401, 2009. 
Goderniaux, P., Brouyère, S., Fowler, H. J., Blenkinsop, S., Therrien, R., Orban, P., and Dassargues, A.: Large scale surfacesubsurface hydrological model to assess climate change impacts on groundwater reserves, J. Hydrol., 373, 122-138, 2009.

Gómez-Hernández, J. J., Sahuquillo, A., and Capilla, J. E.: Stochastic simulation of transmissivity fields conditional to both transmissivity and piezometric data - I. Theory, J. Hydrol., 203, 162174, 1997.

Graham, D. N. and Butts, M. B.: Flexible integrated watershed modeling with MIKE SHE, in: Watershed models, edited by: Singh, V. P. and Frevert, D. K., CRC Press, 245-272, 2006.

Green, T. R., Bates, B. C., Charles, S. P., and Fleming, P. M.: Physically based simulation of potential effects of carbon dioxidealtered climates on groundwater recharge, Vadose Zone J., 6(3), 597-609, 2007.

Hendricks Franssen, H. J.: Impact of climate change on groundwater resources: the need for integrative approaches, Int. J. Climate Change Strat. Manage., 1(3), 241-254, 2009.

Hendricks Franssen, H. J., Gòmez-Hernàndez, J. J., Capilla, J. E., and Sahuquillo, A.: Joint simulation of transmissivity and storativity fields conditional to steady-state and transient hydraulic head data, Adv. Water Resour., 23, 1-13, 1999.

Hewitt, C. D. and Griggs, D. J.: Ensembles-based predictions of climate changes and their impacts, Eos Trans. AGU, 85(52), 566, 2004.

Hsu, K. C., Wang, C. H., Chen, K.-C., Chen, C.-T., and Ma, K.W.: Climate-induced hydrological impacts on the groundwater system of the Pingtung Plain, Taiwan, Hydrogeolog. J., 15(5), 903-913, 2007.

Jyrkama, M. I. and Sykes, J. F.: The impact of climate change on spatially varying groundwater recharge in the Grand River watershed (Ontario), J. Hydrol., 338, 237-250, 2007.

Katz, R. W. and Parlange, M. B.: Overdispersion phenomenon in stochastic modeling of precipitation, J. Climate, 11, 591-601, 1998.

Kleinn, J., Frei, C., Gurtz, J., Lüthi, D., Vidale, P. L., and Schär, C.: Hydrologic simulations in the Rhine basin driven by a regional climate model, J. Geophys. Res., 110, D04102, doi:10.1029/2004jd005143, 2005.

Kristensen, K. J. and Jensen, S. E.: A model for estimating actual evapotranspiration from potential transpiration, Nord. Hydrol., 6, 79-88, 1975.

Loáiciga, H. A.: Climate Change and Ground Water, Ann. Assoc. Am. Geogr., 93, 30-41, 2003.

Madsen, H.: Parameter estimation in distributed hydrological catchment modelling using automatic calibration with multiple objectives, Adv. Water Resour., 26, 205-216, 2003.

Menzel, A., Sparks, T. H., Estrella, N., Koch, E., Aasa, A., Ahas, R., Alm-Kübler, K., Bissolli, P., Braslavská, O. G., Briede, A., Chmielewski, F. M., Crepinsek, Z., Curnel, Y., Dahl, Å., Defila, C., Donnelly, A., Filella, Y., Jatczak, K., Mage, F., Mestre, A., Nordli, Ø., Penuelas, J., Pirinen, P., Remišová, V., Scheifinger, H., Striz, M., Susnik, A., Van Vliet, A. J. H., Wielgolaski, F.-E., Zach, S., and Zust, A. N. A.: European phenological response to climate change matches the warming pattern, Global Change Biol., 12, 1969-1976, 2006.
Michelangeli, P. A., Vrac, M., and Loukos, H.: Probabilistic downscaling approaches: Application to wind cumulative distribution functions, Geophys. Res. Lett., 36, L11708, doi:10.1029/2009g1038401, 2009.

Moustadraf, J., Razack, M., and Sinan, M.: Evaluation of the impacts of climate changes on the coastal Chaouia aquifer, Morocco, using numerical modelling, Hydrogeolog. J., 16(7), 14111426, 2008.

Mualem, Y.: A new model for predicting the hydraulic conductivity of unsaturated porous media, Water Resour. Res., 12, 513-522, 1976.

Nakicenovic, N., Alcamo, J., Davis, G., de Vries, B., Fenhann, J., Gaffin, S., Gregory, K., Grubler, A., Jung, T. Y., Kram, T., La Rovere, E. L., Michaelis, L., Mori, S., Morita, T., Pepper, W., Pitcher, H. M., Price, L., Riahi, K., Roehrl, A., Rogner, H.-H., Sankovski, A., Schlesinger, M., Shukla, P., Smith, S. J., Swart, R., van Rooijen, S., Victor, N., and Dadi, Z.: Emissions Scenarios, A Special Report of Working Group III of the Intergovernmental Panel on Climate Change, Cambridge University Press, Cambridge, 2000.

OcCC/PROCLIM: Klimaänderung und die Schweiz 2050, Erwartete Auswirkungen auf Umwelt, Gesellschaft und Wirtschaft, Bern, 2007.

Onnis, G. A.: Interpreting multiple environmental tracer data with a groundwater model in a perialpine catchment, $\mathrm{PhD}$ Thesis, ETH Zurich, No. 18003, 2008.

Polley, H. W., Johnson, H. B., Fay, P. A., and Sanabria, J.: Initial response of evapotranspiration from tallgrass prairie vegetation to $\mathrm{CO}_{2}$ at subambient to elevated concentrations, Funct. Ecol., 22, 163-171, 2008.

Schär, C., Vidale, P. L., Lüthi, D., Frei, C., Häberli, C., Liniger, M. A., and Appenzeller, C.: The role of increasing temperature variability in European summer heatwaves, Nature, 427, 332336, 2004.

Schmidli, J., Goodess, C. M., Frei, C., Haylock, M. R., Hundecha, Y., Ribalaygua, J., and Schmith, T.: Statistical and dynamical downscaling of precipitation: An evaluation and comparison of scenarios for the European Alps, J. Geophys. Res., 112, D04105, doi:10.1029/2005jd007026, 2007.

Scibek, J. and Allen, D. M.: Modeled impacts of predicted climate change on recharge and groundwater levels, Water Resour. Res., 42, W11405, doi:10.1029/2005wr004742, 2006.

SGK: Die Grundwasservorkommen in Kanton Zürich, Erläuterungen zur Grundwasserkarte 1:25000, Schweizerische Geotechnischen Kommission, Lieferung 69, Kümmerly \& Frei Verlag, Bern, 1986.

Tricker, P. J., Pecchiari, M., Bunn, S. M., Vaccari, F. P., Peressotti, A., Miglietta, F., and Taylor, G.: Water use of a bioenergy plantation increases in a future high $\mathrm{CO}_{2}$ world, Biomass Bioenerg., 33, 200-208, 2009.

van Genuchten, M. T.: A closed-form equation for predicting the hydraulic conductivity of unsaturated soils, Soil Sci. Soc. Am., 44, 892-898, 1980.

van Roosmalen, L., Christensen, B. S. B., and Sonnenborg, T. O.: Regional Differences in Climate Change Impacts on Groundwater and Stream Discharge in Denmark, Vadose Zone J., 6, 554 571, doi:10.2136/vzj2006.0093, 2007. 
Verbunt, M., Zappa, M., Gurtz, J., and Kaufmann, P.: Verification of a coupled hydrometeorological modelling approach for alpine tributaries in the Rhine basin, J. Hydrol., 324, 224-238, 2006.

Wang, S., Kang, S., Zhang, L., and Li, F.: Modelling hydrological response to different land-use and climate change scenarios in the Zamu River basin of northwest China, Hydrol. Process., 22, 2502-2510, 2008.

Warren, G. D.: Drought in the south - implications for the management of groundwater resources, in: Groundwater - Drought, Pollution and Management, edited by: Reeve, C. and Watts, H., Balkema, Rotterdam, The Netherlands, 1994.
Woldeamlak, S., Batelaan, O., and De Smedt, F.: Effects of climate change on the groundwater system in the Grote-Nete catchment, Belgium, Hydrogeolog. J., 15, 891-901, 2007.

Zhou, Y., Zwahlen, F., Wang, Y., and Li, Y.: Impact of climate change on irrigation requirements in terms of groundwater resources, Hydrogeolog. J., 18, 1571-1582, doi:10.1007/s10040010-0627-8, 2010. 